\title{
Organizational Culture "Code": Order Diagnosis of the Ethical-Sensing System
}

\author{
Liudmila Aksenovskaya* \\ Faculty of Psychology, Saratov State University, 410012 Saratov, Russia
}

\begin{abstract}
The article presents order approach to diagnosis of organizational culture. Diagnostics allows to single out the dominant suborders, thus, identifying cultural "code", which is composed of the first letters of the suborder names. In the process of analysis of 18 selected cases of organizational culture diagnostics, which had been carried out within the framework of the order approach to study of organizational culture over the period of time from 2009 until 2018, it was found out that each code is consistently bound to a specific type of task, which is relevant for the organization during the diagnostics period. Six types of codes were singled out, each of them has certain types of organizational tasks to be solved: 1) A-C-F (breakthrough type of activity under conditions of deficit of time); 2) C-A-F (breakthrough type of activity under conditions of ample time); 3) C-F-A (promotes the formation of "corporate religion"), 4) F-A-C (start of activity or its restart); 5) F-C-A (stabilization after a period of extreme activity); 6) A-F-C (organization survival code). It has been shown that understanding the relationship between organization's culture code and its task allows the organization's management to consciously take necessary managerial decisions to correct its organizational culture.
\end{abstract}

\section{Introduction}

The order approach to the socio-psychological study of organizational culture comes from the definition of organizational culture as a complex socio-psychological order of organizational and managerial interactions that are constituted and regulated by systems of ethical senses of interaction participants. That is, the central place in the order model is occupied by the ethical-sensing subsystem of the system of culture's senses. Based on the materials of the empirical study of models of managerial interaction in Russia between 1994 and 2008, three models of managerial interaction were identified, which generated corresponding aspects of organizational culture: "parental" model of managerial interaction (generates the "family" aspect of organizational culture or, in other words, the "family" suborder; provides a value-sensing unity of organization members), "commander" model of organizational culture (generates the "army" suborder of culture; provides goal-oriented unity of organization members) and "pastoral" model of managerial interaction (generates

\footnotetext{
*Corresponding author: liudmila_aksenovskaya@mail.ru
} 
the "church" suborder of culture, provides a sense unity of organization members). Based on these data, we designed the socio-psychological model of organizational culture (order model), where managerial interaction was the model-forming parameter. The model of an integral socio-psychological order of organizational culture (order) simultaneously includes three aspects (suborders): "family", "army" and "church", each of which performs its function as a part of the organizational culture (see above) [1].

Therefore, the system of order diagnostics of organizational culture is based on the model described above. In the diagnostics process, we use the diagnostic system, which currently includes six techniques (two for each level of organizational and cultural system organization level, managerial team level, and top manager level). Thus, we get the result in the form of answers to the questions: 1) regarding the degree of manifestation of each suborder in the integral three-component structure of organizational culture (technique for assessing the degree of suborder manifestation), 2) regarding the degree of each suborder's formation (technique for assessing the degree of formation of suborders), 3) regarding the state of the management system (technique for management system assessment), 4) regarding the level of managerial competencies' formation (technique for assessing managerial competencies), 5) regarding the order type of personality of the leader (technique for assessing the order type of a leader's personality) and, finally, 6) regarding the soteriological level of development of the leader's leadership qualities (technique for assessing the soteriological level of leader's personality development).

The diagnostic procedure can be carried out in its various forms. Among them are individual diagnostic sessions, group diagnostics with the help of an album of diagnostic forms, and computerized polls in the case of work with a large number of participants. Diagnostics is carried out in a self-assessment mode, therefore, objectivity of results is guaranteed through parallel use of conversations, observation, group discussions, and collection of additional data in the organization during the implementation of order projects [2].

One of the main results of order diagnostics of organizational culture at the organization level (large group), which were obtained using the methods for assessing the degree of manifestation of suborders of organizational culture and assessing the degree of formation of suborders of organizational culture, is the so-called "cultural code" of organizational culture. This "code" is written using the first letters of the names of the three main suborders of organizational culture - "family" (F), "army" (A) and "church" (C). Depending on the dominance of a particular suborder, the "code" may look different. For example, codes F-A-C or C-A-F. Other combinations are possible as well.

We analysed 18 reports on the results of order diagnostics in real organizations conducted over the period of time from 2009 until 2018. The reports showed a certain pattern: the resulting "code" of organizational culture is connected with the type of an urgent task, which an organization is to solve at the time of diagnostics.

The aim of the article is to present the typological table of "cultural codes" of organizational culture and a fragment of a case of a specific diagnostic project in an organization to illustrate the data obtaining technique, which is systematized in the table.

\section{Key definitions}

A number of concepts are used within the framework of the order approach, which will be defined below.

Ethical and sensing subsystem of the cultural (organizational and cultural) system is a network of meanings, constituted or attributed by the participants of interaction to standard and new elements of the flow of life. This network of meanings creates subjective cultural group reality. The ethical component of meanings is connected with the influence 
of basic ethical meanings on the process of making decisions regarding the meaning (sense) of this or that phenomenon (action, act, situation).

Ethical and semantic matrix is basic ethical meanings proper, which are the foundation of the ethical and sensing subsystem possessing their own system characteristics (structure, levels, elements, functions). The ethical and sensing matrix includes four pairs of fundamental senses represented by sensing binary oppositions (sensing dyads): life - death, cooperation - conflict, improvement - deterioration, responsibility - irresponsibility. The first dyad (life - death) is correlated with the "family" suborder in the order model of organizational culture (the main value is a person), the second dyad (cooperation - conflict) is correlated with the "army" suborder (the main values are the goal and result), and the third dyad (improvement - deterioration) correlates with the "church" suborder (the main value is Idea, Ideal). The last dyad (responsibility - irresponsibility) is an integral characteristic and the result of ethical and sensing choices made by a person or group under various life and professional circumstances. The criterion for responsible choice is the focus on caring for the interests of the Whole.

The ethical code of culture (ethical and sensing code of culture) contains specific sustainable features of functioning of the ethical and sensing matrix of a particular culture (person, group, organization, ethnic group, confession, historical epoch). Ethical and sensing code of organizational culture (functional level) - is a combination of three suborder characteristics of organizational culture - "family" (F), "army" (A) and "church" (C), which is achieved as a result of summarizing data obtained using all six order methods. The order of letters in the code characterizes the degree of manifestation and formation of organizational culture suborders together with data obtained using other methods. The code correlates with functional ethical senses, therefore representing the "surface" layer of the ethical and sensing subsystem of culture as opposed to the "deep" (basic) layer.

Ethical (ethical and sensing) programme of culture (cultural program) is the complex of substantial, structural and dynamic characteristics of culture. It terms of content (substantial characteristic), we are dealing with principles and basic provisions of culture. The first example is the result of order analysis of the ancient culture of the Cicero era [3] and the second example is the description of the Japanese Corporation's "Sony" integral vision (1950) [4].

Thus, for processing order diagnosis of organizational culture results, their interpretation and the development of actions to change it, four interconnected notions are used as concepts, i.e. ethical and sensing system/subsystem, ethical and sensing matrix, ethical and sensing code, and ethical and sensing programme ("cultural program"). The latter has both substantive and structural and process-related characteristics, i.e. may be an algorithm of actions to change the organizational culture state.

Case-study: Order diagnostics of organizational culture (a technique for assessing manifestation of organizational culture suborders): results of order diagnostics of enterprise " $B$ ".

Below is a report fragment describing diagnostic examination results for enterprise "B". This organization is a large state-owned enterprise working in the field of high technology. The survey involved 4 groups of 8 people (the enterprise management team and employees of 3 large departments, who were selected according to the agreed criteria. The sample is representative). The sample size is 32 people. To illustrate the case study we use the results obtained by applying the technique for assessing manifestation of organizational culture suborders.

The order technique called "Assessment of suborders' manifestation in organizational culture of a regional enterprise" showed the following results (Table 1). 
Table 1. Assessment of suborders' manifestation degree in organizational culture: comparative results of 4 subgroups

\begin{tabular}{|c|c|c|c|c|c|c|}
\hline \multirow[t]{3}{*}{ Groups } & \multicolumn{6}{|c|}{$\begin{array}{c}\text { Organizational Culture Suborders } \\
\end{array}$} \\
\hline & \multicolumn{2}{|c|}{ "Family" } & \multicolumn{2}{|c|}{ "Army" } & \multicolumn{2}{|c|}{ "Church" } \\
\hline & $E S$ & $D S$ & $E S$ & $D S$ & $E S$ & $D S$ \\
\hline $\begin{array}{l}\text { Management } \\
\text { Team } \\
\text { ES: A-F-C } \\
\text { DS: A-F-C }\end{array}$ & $\begin{array}{l}633 \\
33,3 \%\end{array}$ & $\begin{array}{l}875 \\
35,3 \%\end{array}$ & $\begin{array}{l}705 \\
\mathbf{3 7 \%}\end{array}$ & $\begin{array}{l}898 \\
36,2 \%\end{array}$ & $\begin{array}{l}559 \\
29,7 \%\end{array}$ & $\begin{array}{l}706 \\
28,5 \%\end{array}$ \\
\hline $\begin{array}{l}\text { Group №1 } \\
\text { ES: F-A-C } \\
\text { DS: AC-F }\end{array}$ & $\begin{array}{l}640 \\
35 \%\end{array}$ & $\begin{array}{l}797 \\
32 \%\end{array}$ & $\begin{array}{l}614 \\
34 \%\end{array}$ & $\begin{array}{l}846 \\
34 \%\end{array}$ & $\begin{array}{l}557 \\
31 \%\end{array}$ & $\begin{array}{l}849 \\
34 \%\end{array}$ \\
\hline $\begin{array}{l}\text { Group №2 } \\
\text { ES: A-F-C } \\
\text { DS: A-F-C }\end{array}$ & $\begin{array}{l}587 \\
34 \%\end{array}$ & $\begin{array}{l}822 \\
34 \%\end{array}$ & $\begin{array}{l}653 \\
38 \%\end{array}$ & $\begin{array}{l}856 \\
36 \%\end{array}$ & $\begin{array}{l}476 \\
28 \%\end{array}$ & $\begin{array}{l}705 \\
30 \%\end{array}$ \\
\hline $\begin{array}{l}\text { Group №3 } \\
\text { ES: A-F-C } \\
\text { DS: F-A-C }\end{array}$ & $\begin{array}{l}596 \\
35,5 \%\end{array}$ & $\begin{array}{l}803 \\
35 \%\end{array}$ & $\begin{array}{l}654 \\
38 \%\end{array}$ & $\begin{array}{l}791 \\
34,5 \%\end{array}$ & $\begin{array}{l}440 \\
26,5 \%\end{array}$ & $\begin{array}{l}704 \\
30,5 \%\end{array}$ \\
\hline
\end{tabular}

The comparison of diagnostics' results of suborders' manifestation in organizational culture of the enterprise, which was obtained from 4 groups (management team and 3 departments) shows that there is a similarity in assessing the degree of manifestation of culture's aspects in three out of the four compared groups in the existing state (ES): management team and departments №2 and №3. They evaluated the manifestation of suborders with code A ("army”) - F ("family") - C ("church”). Department №1 gave another assessment: F-A-C. At the same time, all 4 groups under comparison placed the manifestation of the "church" suborder in the last place.

The "A-F-C" code is the dominant assessment of the suborders' manifestation degree of the enterprise culture in the existing state (ES). The management team's assessment is shared by most of the departments. At the same time, members of the management team in their comments point out that they constantly feel great tension, as if they were "under siege". They constantly expect harsh criticism "from above" and threats of punishment for unsatisfactory work results.

The general numeral tendency for all 4 groups is the desire to strengthen all three aspects of organizational culture - "family" (care about people), "army" (care about the result of activities) and "church" (care about the uniform sense). At the same time, at the percentage level, the management team would like to reduce the share of the "army" suborder (care about the result) and the share of the "church" suborder (care about general sense) in favor of the "family" suborder (care about people).

Thus, the general culture code of the enterprise is A-F-C.

\section{Typological model of cultural codes}

Processing the results of diagnostics of Russian enterprises' organizational culture, which was carried out over the period from 2009 up to 2018, allowed us to identify a number of 
patterns that describe the relationship between organizational culture' order type and the current state of organizational culture in the form of priority task's type.

The result are presented in the Table 2 .

Table 2. Typology of ethical-sensing cultural codes of an organization

\begin{tabular}{|l|l|l|l|}
\hline № & $\begin{array}{l}\text { Ethical- } \\
\text { sensing } \\
\text { cultural } \\
\text { code }\end{array}$ & Interpretation & Problem Solved by Organization \\
\hline 1. & «A-C-F» & "army-church-family" & Breakthrough under deficit of time \\
\hline 2. & «C-A-F» & "church-army-family" & Breakthrough without any time limit \\
\hline 3. & «C-F-A» & "church-family-army" & Forming "corporate religion" \\
\hline 4. & «F-A-C» & "family-army-church" & Start or re-start of activity \\
\hline 5. & «F-C-A» & "family-church-army" & $\begin{array}{l}\text { Stabilization after a period of } \\
\text { extreme activity }\end{array}$ \\
\hline 6. & «A-F-C» & "army-family-church" & Organization survival task \\
\hline
\end{tabular}

Let us explain the relationship of different code combinations with different types of tasks as follows.

Code "A-C-F" (the task is a "breakthrough" under conditions of deficit of time). The "army" suborder, combined with the "church" suborder, provides the suborder mix called "armed church". This is a characteristic of goal-oriented and at the same time ideologically charged employees - fanatics of their work with the unconditional belief in victory and a strong desire to obtain the result, which are accompanied by willingness to sacrifice almost anything and this belief and are more important that the comfort of the "family" suborder. This code corresponds to project culture (Handy). The code is typical for scientific groups that win and work with grants, special forces units performing a combat mission, search and research expeditions, etc.

Code "C-A-F" (similar "breakthrough" task without time limits, under conditions of ample time) presents almost the same situation, but with a slightly different emphasis: the suborder mix "army of believers" / "fighters-believers", who are making up their plans, accumulating resources and counting forces for the long term perspective. They are a sort of "crusaders", who are going on a long crusade, inspired by their faith in the idea. They are the cultural long-distance runners, who are hardy and persistent. It is a kind of project culture that can be observed in business corporations (you can see the example of "Sony" above, which had a planning horizon of 50 years, the example in state building is the earlier development of the USSR, today - China or, such state projects as a mission to Mars or the lunar program).

Code "C-F-A" (the task of forming a "corporate religion"). This is another combination based on the ideological ("church") component. Instead of project thinking, it is more of a lifestyle development. Achieving the goal is a permanent process of moving towards the Ideal. The task of forming "corporate religion" (J. Kunde) can be found in the ideas of K. Matsushita and his mission of "fighting poverty on Earth", A. Roddick and propaganda of "green" ideology in each of her stores, Merck and the ideal of "preserving and improving human life", Greenpeace, the Red Cross, the Red Crescent and many other organizations where culture, similarly to those of religious organizations, is not related to the time factor as a limiter of existence.

Code "F-A-C" (start or restart of activity). The initial stage of the activity presupposes "manual assembly" of the team, where the leader knows everyone personally and where everyone is a functional continuation of the leader. This is the code of start-ups, where 
development is based on emotional unity and unanimity. Good people with a good task. Examples of cases with activity "restart" were obtained from "old" companies that are focused on adaptation and re-adaptation under constantly changing conditions. However, they are not going to transform radically due to their conservatism, and follow the principle "a bird in hand is worth two in the bush" (for example, enterprises that have been working from the Soviet times).

Code "F-C-A" (stabilization after a period of extreme activity). The organization's culture has this code during the period of relative "rest" after achieving a significant goal (for example, fulfilling a complex state order and not having the next order to fulfill). The code is also characteristic of the agricultural enterprise whose drops in activity are determined by seasonality of work.

Code "A-F-C" (organization's survival task). The code has been identified in the defense industry complex. The result seems to be paradoxical at first sight, since we are talking about large organizations with state ownership, which are often monopolists in their fields. However, more detailed study of the state of enterprises confirms the correctness of this particular interpretation of the task, faced by an organization. For example, for some of these enterprises, the issue of survival is the issue of consolidation in their traditional markets under changed management conditions and the issue of returning to previously lost markets, while for others it is constant tension because of the monitoring and rating systems used by superior structures. Our case illustrates this type of situation.

\section{Conclusion}

Any diagnostic procedure ends with the assessment of the diagnostic object's condition and, in some cases, with a forecast. In our case, the result of order diagnostics of organizational culture allows us not only to find out what the organizational culture of the enterprise is and what it is striving for, but also to find out what task the organization is really working on, and in what condition it is. In this case, the cultural code (ethical-sensing code) acts as a symptom of the underlying process. Such knowledge allows an organization to increase the awareness of its existence, to understand itself and its conditions better. However, the presence of a typological model of cultural codes shows more, namely, a certain type of choices and opportunities space, within which an organization can make decisions about its actions.

\section{References}

1. L.N. Aksenovskaya, Order model of organizational culture (Academic Project, Moscow, 2007)

2. L.N. Aksenovskaya, Order diagnostics of organizational culture (Science, Saratov, 2016)

3. L.N. Aksenovskaya, Nature of gods and nature of people: the ideal's function in the ethical-sensing program of the ancient culture (Neolit, Moscow, 2017)

4. J. Collins, J. Porras, Built forever (Stockholm School of Economics in St. Petersburg, St. Petersburg, 2004) 